\title{
PACKAGING WASTE ECONOMY: INSIGHT INTO EFFICIENCY OF MONOPOLISTIC AND COMPETITIVE WASTE MANAGEMENT SYSTEMS IN THE EU
}

\author{
Aleš Rod ${ }^{1}$ \\ Pavel Peterka ${ }^{2}$ \\ Radek Soběhart ${ }^{3}$
}

DOI: https://doi.org/10.31410/LIMEN.S.P.2019.151

\begin{abstract}
This paper reviews different packaging waste management systems in the member states of the EU, organized as Extended Producer Responsibility (EPR) systems. The principle of responsible waste management in EU is influenced by policy goals and assignments. Individual member states must ensure that set waste management goals are met. The individual Member States comply with these goals using different regulatory instruments as EU does not set how these goals are to be achieved. Therefore, there are various systems in individual countries that achieve different results. Topic of this paper offers unique opportunity to compare efficiency of different regulatory tools in each country. There are two major groups into which this paper categorizes individual packaging waste management systems: monopolistic systems, and competitive systems. Comparison of results and cost effectiveness of individual packaging waste management systems helps to seek optimal organization of packaging waste utilization systems.
\end{abstract}

Keywords: Waste management, Extended producer responsibility, Producer responsibility organization, Regulation.

\section{INTRODUCTION}

$\mathrm{M}$ odern society of today, s world cannot do without support of values that are linked to problem of public goods, sustainable development, nature conservation and other areas that are in so-called public interest. In mentioned areas individuals usually come to an agreement on essence of the idea - protection of nature is a good thing, but we very often lack the willingness to pay for such things - I do not want to pay, make someone else or the state to pay for it. This important aspect leads to redefinition of such activities to higher societal level with so called public interest, or directly to public goods itself that are provided by state through a combination of regulations and fiscal policy.

Same principle goes for the activity of state institutions in the field of waste management, more precisely in the field of sorting and recycling of packaging waste. Primary focus here is also on protecting the environment and on perverse motivation of a rationally behaving individual in form of transferring of costs and responsibilities on other members of society which leads to a situation where there is no spontaneous motivation to sort and recycle packaging waste to a sufficient extent. This is exactly why a political goal expressed by mandatory levels of sorting and recycling of waste in member states of European Union was institutionalized.

\footnotetext{
1 Jan Evangelista Purkyně University in Ústí nad Labem, Moskevská 54, Ústí nad Labem, Czech Republic

2 Jan Evangelista Purkyně University in Ústí nad Labem, Moskevská 54, Ústí nad Labem, Czech Republic

3 Jan Evangelista Purkyně University in Ústí nad Labem, Moskevská 54, Ústí nad Labem, Czech Republic
} 
This binding political goal thus artificially created an area in which the motivations of the individual actors are given by obligations arising from their position and the effort to meet the political objective at the minimum cost (the regulator regulates and controls, the object is regulated). However, this area is not a standard market with characteristic supply and demand, so it is not possible to apply the basic apparatus of neoclassical economic theory that is commonly used to explain the processes in the markets. This issue is one of the key issues of the following lines.

\section{REGULATION OF WASTE MANAGEMENT}

In the case of policies that are related to environmental protection in waste management, it is rather the solution of problems that are caused by negative externalities that is on the agenda of the day. Economics describes possible solutions to problems caused by externalities:

1. Negotiation between affected agents as Coase explains (1960): In terms of clearly defined and easily enforceable property rights, it is more efficient for two agents affected by externality to bargain and agree on a solution than risking a legal dispute at the court of law. For example, a farmer that fertilizes his field to increase his production of crops offers a compensation to an owner of a pond that is polluted by farmers actions. The problem of negative externalities is solved after both parties agree on an amount of compensation. Coase theorem only works if transaction costs of such bargaining are zero or at least close to zero.

2. A state intervention that was described by Pigou (1920): Stat creates barriers (conditions to enter the market, subsidies and taxes, sanctions and fines) using his regulatory power to behavior that would be associated with the emergence of negative externalities. State uses its regulatory power to create conditions in which the generation of negative externalities is difficult and costly. State can for example introduce a law that sets rules on how to manage waste - obligation to ensure the collection of waste, fine for illegal disposal of waste, etc.

Regulating waste management policies is nothing more than creating barriers in the field of waste management to prevent the emergence of negative externalities or to eliminate them as much as possible. The principle of Pigouvian tax is usually implemented, because the conditions that are necessary for Coase theorem to work efficiently are unrealistic in most European countries.

\section{EXTENDED PRODUCER RESPONSIBILITY}

Policy goals of EU in the field of waste management are not accompanied by binding instructions on how the targets are to be met. Which means that every member country has the opportunity to come up with a solution of their own. This led to a mix of objectives and instruments that turned European waste management into a unique laboratory for economics of regulation. Very effective concept of transferring private bargaining to a specific area that is explained by Palmer and Walls (2016) and that is called Extended Producer Responsibility (EPR) emerged out of this laboratory.

In the case of packaging waste, the principle so-called EPR (Extended Productivity Responsibility) is most often applied. The idea of the EPR concept is very broad and is based on belief that producers should be both physically and financially responsible for environmental impact of their activities. The EPR principle is de facto based on the idea that producer in order to distribute its products and sell it to the consumer must protect these products by some kind of packaging. But because this packaging is not part of the consumption, the manufacturer should ensure that it is disposed of in accordance with environmental protection and sustainability in waste management requirements. The consumer's responsibility to dispose of the packaging of purchased goods is 
therefore transferred to the producer, who must ensure that packaging waste does not adversely affect the environment. Under this principle, manufacturers provide the supervision of the circulation of packaging material that is used for commercial purposes, including its collection, subsequent recycling and recovery. In general, as Palmer and Walls (2016) mentions, the EPR is the part of PPP concept (Polluter Pays Principle), where the costs of waste utilization are transferred to polluter, the packaging waste producer. The system is trying to internalize externalities.

\section{ORGANIZATION OF WASTE MANAGEMENT MARKETS}

Manufacturers are willing to fulfil their responsibilities within the collective scheme in EPR systems. This collective system then organizes collection and other waste management services and generates significant economies of scale.

The collective system has the prerequisites for establishing a sufficiently dense and accessible collection network to collect waste from all involved manufacturers. Therefore, it is not necessary for each producer to set up his own containers or for the consumer to transport the waste far from his residence. Within one network, the obligations are met. The system is then financed by fees from the producers who delegated their responsibilities to the system. Fees are mostly derived from the volume of generated waste. Its operator, besides waste collection, often performs other activities, such as educating consumers and supervising compliance with the rules and limits set by law.

As mentioned above, there is no unified form of collective system in the EU. Each country can thus set its own system operating rules. This creates considerable diversity between different systems in Europe. They differ, among other things, in the ownership structure where the collective system can be owned, for example, by the producers, the state, the investment fund or another private company. The operator of the system can either operate as a single operator or there can be more operators within one country. If there are more than one operator, there may be so-called division of the system, where each operator has its scope. The distribution may be based on the type of waste, material, or region. The division can either be unrivaled or rivaled. In the first case, the scope of the operators does not overlap and in the other, the operators can compete.

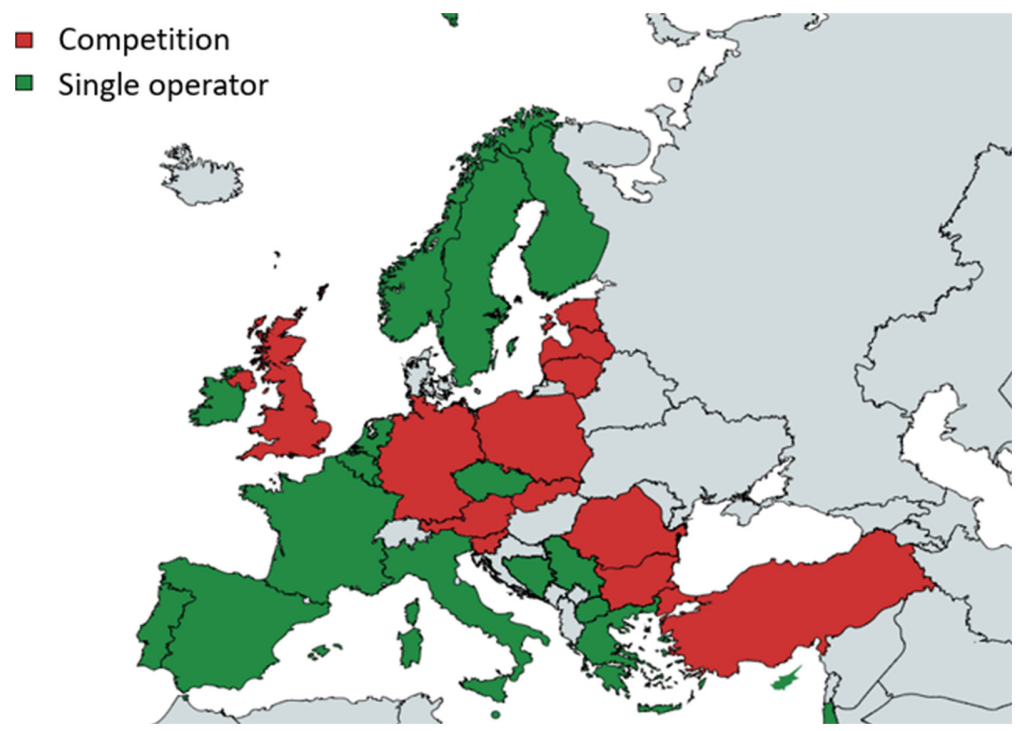

Figure 1. Breakdown of EU member states with regard to the organization type of their waste management system

Source: Rod, Reis, Benko 2016 
In the EU, with regard to the functioning of the waste management system, member states can be divided into two groups:

1. Member States with a single operator system: (16 countries): Czech Republic, France, Belgium, Netherlands, Ireland, Finland, Denmark, Norway, Sweden, Spain, Cyprus, Greece, Italy, Portugal, Hungary, Luxembourg.

2. And to countries with a system where 2 or more operators compete (12 countries): Austria, Germany, the United Kingdom, Poland, Estonia, Romania, Lithuania, Latvia, Slovakia, Slovenia, Bulgaria, Malta.

\section{EPR SYSTEMS: SINGLE OPERATOR VS COMPETETIVE MODEL}

Difference between the competitive and monopolistic organization of the system operators does not seem to be apparent from the point of view of the officially reported achieved rates of recycling and utilization. Although this statement is in contradiction with general assumptions of neoclassical economic theory, competition between collective system operators does not create significant advantages over monopoly arrangements. The opposite is true. Practice shows that natural market principles logically do not occur on a regulated market.

The packaging waste recycling market, however, differs significantly from the market defined by e.g. Simpson (2015). Here are the main differences: As opposed to the market defined by economic theory, the packaging waste market does not spontaneously arise. Since there was a policy goal to create a system for internalizing the packaging waste externalities, a sorting and recycling system was set up and defined by the policy objectives. This politically created system of internalization of externalities is called the „market”, see below.

The market defined by economic theory is defined primarily by the demand based on the preferences of the members of the society that supplier seeks to saturate by its products and services. Demand means willingness to pay for something that increases utility. In the field of sorting and recycling of packaging waste, there is no spontaneous demand for recycling because there is a lack of willingness to pay for the increased utility caused by it. There is also no spontaneous supply.

On market defined by economic theory is a clearly identifiable demand side (an individual who is willing to pay for the increase of utility through the consumption of goods) and the supply side (an individual who saturates the supply with goods he manufactures and / or delivers on the market). In the packaging waste market, there is no definition of supply and demand - the demand for ,mandatory sorting and recycling” is not a demand of a consumer, nor is it a demand of packaging waste producer. It is not even a demand of a regulator who does not offer or demand anything, regulator only tries to internalize negative externalities in the environment.

The cost of goods on a market defined by economic theory is defined by the interaction between supply and demand, i.e. in a simplified way between the production costs of the supplier and the willingness to pay of the agent who is demanding goods. In market for sorting and recycling of packaging waste, there is no similar scheme. The spontaneous pricing mechanism is replaced by the quantification of the system costs that is divided among participants of the system, which are involved in its financing.

On a market defined by economic theory, competition has clear positive effects. Competing entities want to attract as many clients as possible, so they try to combine attractive factors such 
as lower product price, higher product quantity on one money unit spent, pressure on product quality, pressure on product innovation, etc. In the sorting and recycling of waste system, however, the fulfilment of these desirable targets is not triggered by higher number of competing entities, because ,product” is defined as a service for which there is de facto there no demand. Consequently, competitors will only try to reduce costs for obligated participants, which will logically lead to a lack of resources that are necessary to meet the desired policy goal.

An entry of a new entity that wishes to get a share in the system and its associated funds, it can only do three things: increasing the total cost of the system, choosing only the most lucrative parts of the system to optimize its cost structure (cherry picking), or fraudulent behavior (e.g. adjustments to financial statements, export / import of packaging waste abroad, etc.). All these strategies are undesirable from the point of view of meeting the political goal, as they do not increase the effectiveness of the system.

On a market defined by economic theory, the market is divided according to the economic criteria, which are chosen by the demanding side on basis of the quality of the offered farm. In the sorting and recycling system, even in the light of the lack of information, they cannot evaluate the quality of the service and therefore they prefer the solution that is cheapest. In a transparent system with one PRO, there is no room for cost reduction or service quality improvement, without having an impact on meeting the increasing political goals. Paradoxically, more entities create room for less efficiency.

The aspects mentioned above are reflected in the performance of systems with one PRO operator (so-called monopoly system, single-operator system) and multi-operator systems (so-called competitive system, multi-operator system).

\section{EPR SYSTEMS: FEES COMPARISION}

The idea that a narrow circle of major PRO owners can theoretically use their position to the detriment of the rest of the obligatory industry is rational, but in practice of a monopoly provider not possible. In the Czech system, as well as in many other monopoly operators, all public fees are minimized - there is no price discrimination on either the obligatory industry or the municipalities involved, especially the differences in small, remote settlements (very costly from the point of view of recycling) and large, infrastructure-equipped cities (very profitable from the point of view of recycling). Since the only system on the market does not have reason to hide its prices from competitors, it enables price discovery to analyze the cost and effectiveness of the system.

The collective recycling system is a monopoly in Austria, Belgium, the Czech Republic, France and the Netherlands. It is competitive in Germany and the UK. Calculated as fees per ton of utilization (household waste) per capita. At first glance, costs in the UK seem to be the lowest lower, but the manufacturer's fees cover only about $10 \%$ of the total cost. The actual cost is about 10 times that. In France, fees cover $75 \%$ of the costs. In other countries it is $100 \%$.

If we compare this situation with the competitive system in Germany, where the fees of the obligatory industry are subject to business secrets, the price discrimination (disadvantage) of smaller packaging producers definitely occurs. Trade secrecy in the field of fees does not lead to a transparent environment where there would be no preference for certain obligated companies. 
In Germany, Austria and other competing PRO countries, this behavior is a major problem, especially in the form of high transaction costs of smaller entities facing price discrimination, who must oppose it by forming municipality associations, lawsuits or lobbying to establish a legal obligation to publish price lists and thus eliminate price discrimination.

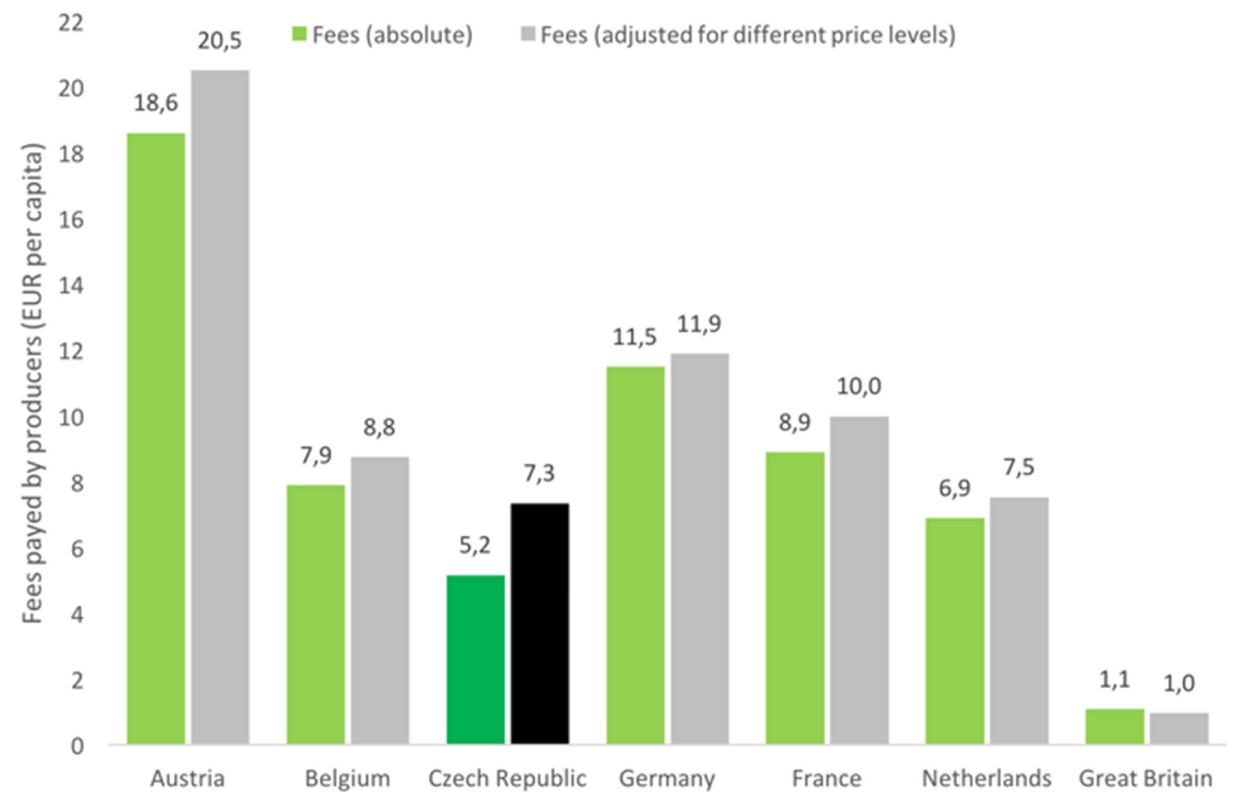

Figure 2. Fees of obligatory industry in individual countries

Source: (Monier et al., 2014); Eurostat, data from 2010-2012

It is precisely on the existence of intermediaries who help to negotiate more favorable conditions that we can demonstrate from the point of view of economic theory the fundamental inefficiency. In Austria, smaller municipalities join associations to try to achieve a more favorable price level. But even negotiations are associated with additional costs.

Based on recent development in selected EU countries as also e.g. PRO EUROPE (2016) mentions, it can be quite surprising to say that a competitive system not only does not generate better results than a single operator system but also brings a number of disadvantages such as higher transaction costs, low system transparency, higher administration requirements, higher motivation to fraud, more room for avoiding obligations by manufacturers and system operators, and hence higher demands for regulation and control by the state.

Practical experience shows us that natural market principles do not logically occur on a regulated market. This also has an impact on the performance of the entire industry. The obvious difference does not appear to be between the competitive and monopoly organizations of the system operators nor in terms of officially reported recycling and recovery rates.

This is demonstrated by official results of packaging waste systems from EU countries that are available from an official statistical report done by Eurostat. Results of individual systems are available in Figure 3, which offers comparison of packaging waste recycling rates in selected EU countries from 2017 in \%. EU 28 average lies at $67 \%$ recycling rate of packaging waste. The best result of $84 \%$ recycling rate of packaging waste was achieved in Belgium with single operator system. Second best of $78 \%$ is achieved in Netherlands that also has single operator system. Third (Denmark) best and fourth (Czech Republic) best results are also achieved with a single operator system. 
This situation does not offer a hard evidence that single operator systems are better than competitive models. It simply shows that desired results are achievable with "monopoly" systems and that they do not lag behind in context of waste management in EU.

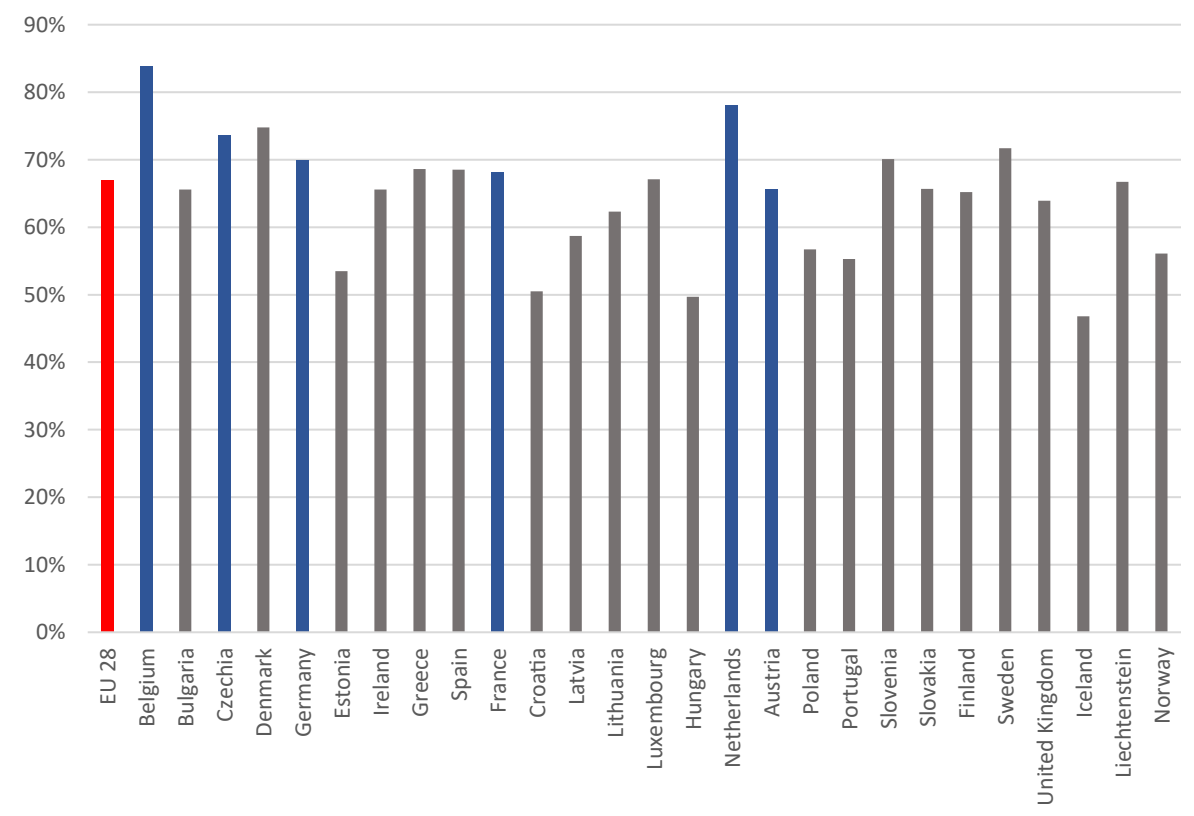

Figure 3. Domestic packaging waste recycling rates (\%) in selected EU countries in 2017

Source: (Eurostat, 2019); Eurostat, data from 2017

\section{FUTURE RESEARCH DIRECTIONS}

As far as the extended producer responsibility is, according to the ongoing EU legislation directives SUP (Single Use Plastics) and CEP (Circular Economy Package), a preferred approach to organizing waste economy systems in EU member states, we can expect a massive implementation of these structures into practice, both monopolistic ones (single operator) and competitive ones (multi operators). Different implementation conditions, geographic dispositions, socio-demographic structures and other factors will provide an excellent environment for further research, mainly from a perspective of efficiency (meeting EU goals) and economy (costs transposed into waste collection fees). Our future research will be pointed on international comparisons using actual data as well as modelling optimal structures of waste economy systems in individual countries with respect to multifactor analysis.

\section{CONCLUSION}

According to mainstream economic theory' conclusions, a market competition brings substantial social better offs in terms of pricing, qualitative and quantitative aspects, availability, development of new products, etc. This opinion, as a mantra, is mentioned when setting regulatory structures in individual market segments, waste economy included. This conclusion, without any doubts, is valid for any economic market with demand side and supply side, both powered by standard economic preferences. However, when we talk about packaging waste management systems, we do talk about a very special market - preferences of demand side are set rather by regulation (political goals) than spontaneous utility-maximizing action, while supply side is boosted by public money (grants and subsidies, public tenders, etc.) and rent-seeking rather 
than spontaneous profit-seeking. Thus, mainstream economic conclusions about competition are not applicable automatically. In our analysis, we were unable to reject the null hypothesis that competitive packaging waste economy systems provide better results in terms of economic efficiency, material efficiency, pricing, etc. We observed that some monopolistic and competitive systems are able to generate high and low recycling rates as well as high and low fees for its participants, however we are unable to conclude that competition brings better results. Actually, the opposite is true. Monopolistic systems, thanks to clear structure, transparent pricing, no rent-seeking side expenditures, etc., provide very high recycling rates of individual materials with low fees and well-defined responsibility for all areas, marketing or social education included. This must be a very important message for all decision-makers in the EU, who would blindly make pressure for establishing competitive packaging waste economy systems. When dealing with non-standard markets, competition does not routinely mean better results.

\section{ACKNOWLEDGEMENT}

This research was supported by the Jan Evangelista Purkyně University in Ústí nad Labem, Czech Republic as a part of the project OPVVV "Smart City - Smart Region - Smart Community" (CZ.02.1.01/0.0/0.0/17_048/0007435).

\section{REFERENCES}

Brian P. Simpson, B. (2015). Two Theories of Monopoly and Competition: Implications and Applications. Journal of Applied Business and Economics, [online] 11(2), pp.1-7. Accessible at: http://na-businesspress.homestead.com/JABE/Jabe112/SimpsonWeb.pdf [Accessed 22 Nov. 2015].

Coase, Ronald (1960) The Problem of Social Cost, Journal of Law and Economics, The University of Chicago Press

Eurostat. (2019) Packaging waste statistics 2017. Accessible at: https://ec.europa.eu/eurostat/statistics-explained/index.php/Packaging_waste_statistics

Monier, V., Laureysens, I., Watkins, E., Reisinger, H., \& Porsch, L. (2014). Development of Guidance on Extended Producer Responsibility (EPR): Final Report. Accessible at http:// ec.europa.eu/environment/waste/pdf/target_review/Guidance $\% 20$ on $\% 20 \mathrm{EPR} \% 20-\% 20$ Final\%20Report.pdf

Palmer, K., \& Walls, M. (1999). Extended Product Responsibility: An Economic Assessment of Alternative Policies. Accessible at http://www.rff.org/files/sharepoint/WorkImages/Download/RFF-DP-99-12.pdf

Pigou, A. C. (1920). The Economics of Welfare. London: Macmillan.

PRO Europe. (2016). Participation Costs Overview 2016. Accessible at http://www.pro-e.org/ files/Participation-Costs_2016.pdf

Rod, A., Rais, J., Benko, T. (2016) Efficiency of the Waste Sorting System in the Czech Republic and Chosen EU countries 